\title{
Vision and perception of community on the use of recycled water for household laundry: A case study in Australia
}

\author{
Bandita Mainali ${ }^{\mathrm{a}}$, Thi Thu Nga Pham ${ }^{\mathrm{a}}$, Huu Hao Ngo ${ }^{\mathrm{a} *}$, Wenshan Guo ${ }^{\mathrm{a}}$, Clayton Miechel ${ }^{\mathrm{b}}$, Kelly O’Halloran $^{\mathrm{c}}$, \\ Muthu Muthukaruppan ${ }^{\mathrm{d}}$, Adnrzej Listowski ${ }^{\mathrm{e}}$ \\ ${ }^{\mathrm{a}}$ Centre for Technology in Water and Wastewater, School of Civil and Environmental Engineering, University \\ of Technology Sydney, Sydney, NSW 2007, Australia \\ ${ }^{\mathrm{b}}$ Port Macquarie-Hastings Council, Port Macquarie, NSW 2444, Australia

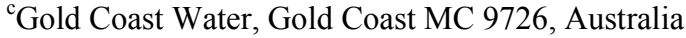 \\ ${ }^{\mathrm{d}}$ City West Water, Sunshine VIC 3020, Australia \\ ${ }^{\text {e}}$ Sydney Olympic Park Authority, Sydney Olympic Park, NSW 2127, Australia
}

*Corresponding author, Email: h.ngo@uts.edu.au, Tel: +61 (2) 95141693, Fax: + 61(2) 95142633

\begin{abstract}
This study investigates the community perception of household laundry as a new end use of recycled water in three different locations of Australia through a face to face questionnaire survey $(n=478)$. The study areas were selected based on three categories of (1) non-user, (2) perspective user and (3) current user of recycled water. The survey results indicate that significantly higher number $(70 \%)$ of the respondents supported the use of recycled water for washing machines $\left(\chi^{2}=527.40, \mathrm{df}=3 ; \mathrm{p}=0.000\right)$. Significant positive correlation between the overall support for the new end use and the willingness of the respondents to use recycled water for washing machine was observed among all users groups $(r=0.43, p=0.000)$. However, they had major concerns regarding the effects of recycled water on the aesthetic appearance of cloth, cloth durability, machine durability, odour of the recycled water and cost along with the health issues. The perspective user group had comparatively more reservations and concerns about the effects of recycled water on washing machines than the non-users and the current users $\left(\chi^{2}=52.73, \mathrm{df}=6 ; \mathrm{p}=0.000\right)$. Overall, community from all three study areas are willing to welcome this new end use as long as all their major concerns are addressed and safety is assured.
\end{abstract}

Author keywords: Community; vision; perception; end use; recycled water; household laundry.

\section{Introduction-}

Australia targets to increase the water reuse from $16.8 \%$ in the year $2009 / 10$ to $30 \%$ per year in 2015 (Whiteoak et al., 2012). To meet this aggressive water recycling targets, more recycled water schemes together with new end uses should be further explored and 
developed. After agriculture, the household sector falls as the second highest water user in Australia (ABS 2012). Therefore, due consideration should be given for conservation of more household water with recycled water. Recycled water supply in form of dual reticulation system has already begun in some suburbs of Australia. However, the existing end uses of recycled water in such systems are limited for landscape irrigation, car washing and toilet flushing. Hence, adding up new end uses of recycled water to the existing end uses is a must for system optimization and sustainability. Washing machine as a new end use of recycled water in dual reticulation system is well recognised for its great potential benefits. The influence of laundry water consumption is significant (almost 20\%) on household water consumption of different states of Australia (ABS, 2004; Mainali et al., 2011) and most of the countries of the world ( Pakula and Stamminger, 2010). Few studies on the use of recycled water for washing machines (O’Toole et al., 2008; Storey, 2009; Mainali et al., 2011a, 2013; Chen et al., 2012) were carried out. However, studies investigating on social aspects to analyse public's acceptance and their concerns on this new end use are sparse.

It is a fact that successful implementation of a wastewater reuse project depends not only on its technical and environmental feasibility, but primarily on the support and the acceptance from the general public. Dishman et al. (1989) concluded that "the technical aspects of potable water reuse can be resolved, but the issue of public acceptance could kill the proposal". There are evidences of many recycled water projects which have failed due to lack of community support (Mainali et al., 2011b). These projects include not only the (indirect) potable reuse schemes but also the non-potable reuse projects including one in the Netherlands (Hurlimann and Dolnicar, 2010). To introduce any new end use of recycled water, it is without doubt a major challenge to achieve the public acceptance and support, especially when the use is with more personal contacts. Many researchers (Hartley, 2003; Po et al., 2003; Marks, 2006; Hurlimann and Dolnicar, 2010; Mainali et al., 2011b) advocate that 
no program using recycled water can be initiated without public acceptance. It is therefore very crucial to identify the nature of public response regarding the use of recycled water in washing machines. Since long, majority of studies have investigated public acceptance of recycled water for various uses. Pioneers in this field (Bruvold and Ward, 1970; Bruvold, 1972) and many others (Stone and Company, 1974; Sims and Baumann, 1974; Olson et al., 1979; Bruvold et al., 1981; Milliken and Lohman, 1983; Lohman and Milliken, 1985; Ahmad, 1991; Madany et al., 1992; Sydney water, 1999; Jeffery, 2002; Hills et al., 2002; ARCWIS, 2002; Friedler et al., 2006; Marks et al., 2006; Hurlimann, 2006; Hurlimann 2007, Roseth, 2008; Alhumoud and Madzikanda, 2010; Pham et al., 2011) are some of the studies conducted basically in USA and Australia and some from UK, Qatar, Bahrain, Kuwait and Israel. Table 1 provides an overview of these studies (except Jeffery, 2002). It is noted that only household uses of recycled water from these studies are taken into consideration for this study. In all studies, highest level of opposition is observed as the use becomes increasingly closer to personal physical contact.

It is observed that since late $1960 \mathrm{~s}$, studies investigating community attitude towards the use of recycled water have been observed in USA whereas in Australia, detail studies began only in the late 1990s and in rest of the countries very few numbers of similar studies are carried out till date. Almost all (except Bruvold et al., 1981; Madany et al., 1992; Hills et al., 2002) studies cover the willingness of the community to use recycled water for washing machines. In general, the percentage opposing the use is more or less the same for all studies. However, the detail investigation of people's attitude towards this new end use for recycled water has not been addressed in these studies as their study purpose was different. Pham et al. (2011) carried out a detail study on community attitudes regarding this new end use. However, the survey sample size was small and only covers the Sydney region. Hence, this study incorporates different locations of Australia with a larger sample size $(n=478)$. It 
basically analyses the community perceptions, concerns and reservations to use recycled water for washing machine. The further conditions required making the community more confident and comfortable to use recycled water in washing machines are explored. Moreover, the comparative study regarding the attitude and concerns of the non-users, perspective users and the current users of recycled water have been carried out. The study can be of great value to the decision makers who intend to introduce the washing machine as a new end use of recycled water in the dual reticulation systems for substantial conservation of drinking water.

Table 1.

\section{Methodology-}

\subsection{Survey plan design and execution}

Reviewing several published articles on public attitude surveys, it has been observed that basically such surveys can be divided into three main categories, each dealing with a different situation. The survey sample size in the study incorporated all three categories.

- The first category (Non-user of recycled water) consists of studies that attempt to investigate the attitude of the general public towards the water reuse schemes to establish a general idea. The study was carried out in few suburbs (Dunbogan and Laurieton) of Port Macquarie where there may be but yet no robust plan of recycled water supply to the community.

- The second category (Perspective user of recycled water) seeks public opinion on actual, forthcoming water reuse projects. This study was carried out in few suburbs (Manor Lake and Wyndham Vale) of Melbourne where the communities are already equipped with the dual reticulation system and are expecting to receive recycled water supply very soon. 
- The third category (Current user of recycled water) examines public attitude in places where reuse schemes have already been put forward in place. This study was carried out in Newington of Sydney where the communities have already been supplied with recycled water.

\subsection{Questionnaire Survey and Data analysis}

A questionnaire was developed based upon the literature review and the feedbacks from the previous study (Pham et al. 2011). The study population included adults above the age of 18 from different cultural backgrounds and different socio-demographic backgrounds. Interviews were conducted at different public areas such as shopping centres, parks, swimming pools, outside public schools, stations and door to door at their residences.

The statistical package for social science (SPSS) was used for the data analysis. Descriptive statistics were employed to illustrate the respondents' characteristics, their responses, as well as possible differences between sites or groups of people. Wilcoxon Signed Ranks Test was employed to rank the most important factor according to the general community. Chi-square tests $\left(\chi^{2}=\right.$ Chi-square; $\mathrm{df}=$ degree of freedom) were carried out to provide significance levels for the observed differences whenever needed. The relationship between the various variables was investigated using cross-tabs thereby analysing the Pearson correlation coefficients as well as chi-square tests. Public concern of the use of recycled water was compared using a Chi-square test of a contingency table and a post-hoc multiple comparison test analogous to the Tukey's test (Zar, 2010). All the coefficients reported in the Section 3 are significant at the 0.05 level or better.

\section{Results and Discussion}

\subsection{General features of three study sites}


The general features and the comparative chart in terms of household size, washing machine type, washing frequency and other general details of three study sites are presented in Table 2. A total of 478 people from three study areas including $55 \%$ of females and $45 \%$ of males completed the questionnaire. Percentage respondents in Port Macquarie represent the proper sample representation of population of Port Macquarie which comprises $48 \%$ of males and 52\% of females (ABS 2011a). The ratio of respondents in Melbourne (only 37\% of males) however is not an exact representation of the population of Melbourne which comprises of $49 \%$ of males and $51 \%$ of females (ABS 2011b). This could be attributed to the reason that door to door survey was carried out in this area and mostly the ladies were more likely to participate for the survey in their homes. In Sydney, number of males completing the questionnaire is higher than females which are in contrast to Port Macquarie and Melbourne $\left(\chi^{2}=8.25, \mathrm{df}=2 ; \mathrm{p}=0.000\right)$. However, this can be better explained by the fact that many areas in greater Sydney is characterised with high sex ratios which includes Homebush Bay Silverwater where there were 121.9 males for every 100 females as per the statistical report from ABS (2011c).

The majority of households in the study areas are small sized family or the nuclear family (1-3 people) followed by households with the medium sized family (4-6 people) as presented in Table 2.. In Port Macquarie, almost third quater of households in the study areas are small sized family which reflects the average household size of Port Macquarie which is 2.3 persons per dwelling as per the report of ABS (2011). The household size in Port Macquarie is smaller than the average of all three study sites; however, the washing frequency of the households in Port Macquarie is higher than that of the average of three study areas. In an average, most of the households washing frequency is 3-4 times (40\%) or 1-2 times (34\%) a week whereas majority of households (77\%) in Port Macquarie wash the clothes 5-6 times a week. 
The survey results revealed that almost all participants use washing machines in their home for washing clothes which agrees very well with the report from ABS (2008) which states that $97 \%$ of households in Australia have washing machines. The number of top loading washing machines is higher (almost 65\%) than the number of front loading washing machine as suggested by ABS (2011c) which states that $68 \%$ of households use top loading washing machines in Australia. The number of front loading washing machine in Sydney and Melbourne are quite higher than in Port Macquarie (Table 2). Both the study areas in Sydney and Melbourne are newly developed areas and therefore new setup might have given rise to the purchasing of more water efficient and energy efficient option which is frontloading washing machine compared to top loading (Mainali et al., 2011). However, the dominant type of washing machine is the top loading washing machine. Use of water and energy efficient devices should be given more priority for a sustainable future. In this study, significantly higher number (almost third quater) of the respondents support the use of recycled water for washing machines $\left(\chi^{2}=527.40, \mathrm{df}=3 ; \mathrm{p}=0.000\right)$; higher than many other studies previously

conducted (Friedler et al., 2006; Hurlimann, 2006; Roseth, 2008; Alhumoud and Madzikanda, 2010 and Pham et al., 2011).

\section{Table 2.}

\subsection{Concerns and willingness to use recycled water}

Almost $90 \%$ of the total respondents agreed and strongly agreed with the statement that recycled water is an important alternative of potable water for non-potable uses whereas $10 \%$ disagree and strongly disagree with the same. Five different statements were given to the respondents as options to justify their reasons for agreeing recycled water is an important alternative of potable water for non potable purposes. The results indicate the fact that recycled water saves valuable drinking water and concerns for environment were the most important reasons to agree that recycled water is valuable. Majority of participants $(70 \%)$ 
who identified themselves as being supportive of water recycling picked these two statements as their preferred options $\left(\chi^{2}=591.09, \mathrm{df}=5 ; \mathrm{p}=0.000\right)$. Only $6 \%$ of the respondents who supported the use of recycled water prioritise saving money as an important factor. Hence, it is observed that recycled water saves our valuable drinking water and environmental concerns should be emphasized in a public information campaign to motivate them to use recycled water. However, all the reasons are apparently important. Similarly, $6 \%$ of the total respondents preferred health reasons as the option for not agreeing recycled water as a valuable resource where as $2 \%$ selected the statement that recycled water is not clean enough to use.

\section{Table 3.}

The matrix of choices of respondents to express what would make them more confident and comfortable to use recycled water for washing machine is presented in Table 3. Wilcoxon Signed Ranks Test was employed to analyse the most important condition. The results from the test revealed that 'knowing that recycled water saves valuable drinking water' was chosen as the most influencing factor by $82 \%$ of the respondents. The result is statistically valid as shown in Table 3. Positive response for 'having a small unit of pre-treatment of water to assure the quality and safety of water' was shown by $76 \%$ of the respondents. Reading about recycled water being used in washing machines by other customers was chosen by $71 \%$ of the respondents followed by $65 \%$ of positive response for "watching a scientist or expert recommend the use of recycled water in washing machines". Supply of recycled water in a dual pipe system was chosen by $64 \%$ of the respondents as a fact to make them more confident and comfortable to use recycled water for laundry. No significant difference was revealed among other choices though to rank them in an order. Significant difference is observed between HAV and DUAL $(\mathrm{p}=0.049)$. Hence, it is of utmost importance to let the 
community understands that recycled water plays an important role to save the valuable drinking water.

More than $90 \%$ of the respondents from the non-user group as expected reckoned they have no idea if they are receiving recycled water in future. On the other hand, from the perspective user group, half of the respondents reckoned that though they have dual pipe system, they have no idea when they will be receiving recycled water in future whereas $30 \%$ revealed they know they will be receiving recycled water soon. However, almost $70 \%$ of respondents from both the non-user and perspective user groups are happy and very happy about receiving recycled water to their home in future. In current user group of recycled water, almost $85 \%$ of the respondents are happy and very happy about receiving recycled water in their home whereas only $10 \%$ are unsure about it.

Respondents were asked if they are willing to use recycled water for six different end uses of recycled water. Results from Figure 1 clearly show that the percentage of respondents willing to use recycled water decreased gradually from option of watering gardens, to flushing toilets, washing cars, washing cloths, filling a swimming pool and showering in all three study areas. This trend has very well agreed with the conclusion made almost 40 years ago by Bruvold (1972) that people differentiate between the kinds of uses and show the highest level of opposition when asked about close to body uses, such as swimming and bathing. This finding has been replicated in all successive studies on public acceptance of recycled water in Australia (McKay and Hurlimann, 2003; Po et al. 2003; Hurlimann, 2006; Marks et al. 2006; Roseth 2008; Dolnicar and Schäfer, 2009; Pham et al.,2011) etc. However, results from a survey (Ahmad, 1991), that was conducted in Qatar was in severe contrast to most results obtained elsewhere. A large percentage of the respondents opposed the reuse options and no influence of degree of contact was observed. This could be because of the 
different cultural background and religious aspects. Hence, the location plays a huge role in people's attitude.

\section{Figure 1.}

The comparative analysis of willingness to use recycled water for washing machine among three user categories of recycled water has been summarised in Figure 2. The percentage of respondents who are happy and very happy about receiving recycled water in perspective user group and current user group is higher compared to non-user group. However, it is observed that $58 \%$ of respondents in the current user group are willing to use recycled water for laundry whereas only $45 \%$ of respondents are willing for the same in perspective user group. This finding is in line with the statement made by (Dolnicar et al., 2011) concluding that prior experience with using water from alternative sources, increases the stated likelihood of use. On the other hand, $70 \%$ of respondents are willing to use recycled water for washing machine in non-user group. In terms of receiving information about recycled water, the perspective user group is ahead than the non-user group as expected whereas in terms of willingness to use recycled water for laundry, the non-user group is ahead of the perspective user group and so is the current user group. For other end uses like toilet flushing, garden irrigation and car washing there is not significant difference in terms of \%; however, for washing machine the difference is remarkable and significant $\left(\chi^{2}=52.73, \mathrm{df}=6 ; \mathrm{p}=0.000\right)$. The reasons for this can be attributed to the fact that community in Newington, Sydney (the current user group) have already been exposed to the use of recycled water and are observed to be happy with the use so as they are willing to accept the new end use in spite of the higher contacts with the human body. In the perspective user group in Melbourne, people are only mentally and emotionally prepared for using recycled water but they do not have yet physical contact with the same and thus may be more reserved to use it for the uses which involve higher degree of contact. On the other hand, in Port Macquarie it is not yet confirmed 
whether the supply of recycled water in future is guaranteed or not. For this reason, people might have less reservation for using the recycled water for laundry.

\section{Figure 2.}

Another distinct observation was made in the survey that among 478 participants when asked whether they do support the use of recycled water specifically for laundry; almost $70 \%$ support the use. However, respondents when asked for their willingness to use recycled water for laundry along with other end use options, lesser number of respondents (only 57\%) are willing to use recycled water for washing machines. The trend is exactly the same in all three study sites (Fig. 3).

\section{Figure 3.}

This may be because the general public when given many choices differentiate the uses in terms of degree of contact and are more reserved to say yes to the uses with high personal contact. However, when they are focussed specifically for the use of recycled water for a particular purpose like washing machines, they are bit flexible and show less reservation. Further analysis is required to check if it works similarly with each individual end-use. However, in the study, there exists a strong positive correlation between the willingness of the respondents to use recycled water for laundry and the overall support in all three studies ( $\mathrm{r}$ $=0.43, \mathrm{p}=0.000)$.

The concerns of community from three study sites when using recycled water for washing clothes has been presented in Figure 4. Health has been always observed as one of the main concern among the people when use of recycled water is considered. Hence in this survey, to be familiar with core concern of people for using recycled water for laundry, excluding the option health, respondents were asked if they are concerned about the other effects of recycled water on cloth colour, potential damage to cloth, effect on washing machine, potential odour and the increased cost. Surveyors experienced that people consider health as a 
main concern and seek for the option for it. However, other concerns were also given due consideration by the general community.

\section{Figure 4.}

As indicated in Fig. 4, almost all concerns are given due consideration by almost half of the total respondents. Basically, 59\% of the people expressed their concern about the potential odour of the recycled water followed by $54 \%$ of people who are concerned for the aesthetic appearance of the cloth, $50 \%$ of the people are concerned about potential damage to cloth, $48 \%$ of the respondents are concerned about the effects of recycled water on washing machines and $41 \%$ of the respondents are concerned about the increased cost. From, this analysis, it is observed that people support the use of recycled water in washing machine; however, they wanted to be guaranteed in terms of such issues. Wilcoxon Signed Ranks Test was employed to choose the most influential concern but no significant difference was observed ( $p>0.05)$. Therefore, along with the health issue, it is of great importance to address all other concerns listed above with sufficient experimental investigations. Comparing the three study sites, in an average $60 \%$ of the respondents from the perspective user group showed their concerns on the effect of recycled water whereas only $40 \%$ of the respondents from non-user group showed their concern for the same revealing that the perspective users of recycled water are more concerned rather than the non users. This finding is similar with the findings from Higgnis et al., (2002) in which almost $90 \%$ of the respondents who are the perspective user of recycled water showed higher concern for the quality of recycled water whereas only $50 \%$ of the respondents who are the non-user of recycled water showed their concerns. Among the current user group, only $45 \%$ showed their concern on the effect of recycled water. This finding is again in line with the statement made by (Dolnicar et al., 2011) concluding that prior experience with using water from alternative sources, increases the stated likelihood of use. A study undertaken in Denmark investigating the use of 
rainwater and greywater for toilet flushing (Albrechtsen 2002) found out that in the instances of grey water use for toilet flushing, there were several complaints regarding bad smell, with one particular plant shut down because of the complaints. Hence, it is of great importance to understand the attributes of the recycled water fit for use. Positive responses to all of the above concerns demand the higher quality of recycled water for using in washing machines. Hurlimann and Mckay (2006) advocate that recycled water for washing machine needs to be of higher quality. Therefore, it is noteworthy that the targeted communities are clarified and well explained with supporting experimental evidences regarding these issues prior to the implementation of this new end use. Also, commencing this new end use in some of the urban suburbs supplied with dual reticulation system can help immensely to motivate the other target groups for the same.

\subsection{Correlation between the variables}

The correlation between the levels of support using recycled water for washing clothes with age, genders, frequency of washing, place, willingness to use recycled water, attitude about receiving recycled water at home, acknowledgement of recycled water as an important alternative source etc are analysed and presented in Table 4. Positive significant relation is revealed between the household size and frequency of washing $(\mathrm{r}=0.4, \mathrm{p}=0.000)$. However, no significant relationship was found between the machine type and the washing frequency $(\mathrm{p}>0.05)$. In contrast to the results from Melbourne and Sydney, in Port Macquarie weak negative significant relationship exists between machine type and washing frequency $(\mathrm{r}=-$ $0.16, \mathrm{p}<0.05)$ indicating increased washing frequency with front loading type of washing machine. As a part of analysis, it was revealed that $55 \%$ of participants are using powder detergents, whereas $25 \%$ reckoned to use liquid detergents and $20 \%$ are using both. There was no significant relationship between the type of washing detergents and washing frequency. 
Many factors have been investigated in regards to their influence on willingness of using recycled water. Past studies found that some demographic characteristics such as gender, age and education influence attitudes towards recycled water use. However Marks (2004) in his review article found that there is little evidence that demographic factors, apart from gender can predict acceptance of recycled water use. In all three studies, no correlation has been found between age and level of support for using recycled water in washing machine (Table 4) which is in line with the findings on potable reuse by Marks (2004). However, the results revealed no correlation between gender and level of support which matches with some other works (Jeffrey and Jefferson, 2003; Friedler et al., 2006) but contradicts the findings on potable reuse by Marks (2004) and Bruvold (1984). Weak negatively correlated significant relationship exists between gender and acknowledgement of the importance of recycled water and weak negatively correlated significant relationship was found between gender and attitude about receiving recycled water at their homes among the non-user group unlike the current user group and perspective user group. This revealed that from the non-user group, the males were observed to be happier in terms of receiving recycled water at homes than females and also males were way ahead than females to agree that recycled water is important. These findings are in line with the findings from many researchers (Baumann and Kasperson, 1974; Lohman and Milliken, 1985; Tsagarakis et al., 2007; Nancarrow et al., 2008; Dolnicar and Schafer, 2009).

In all studies, significant positive relationship was observed between acknowledgement of importance of recycled water and attitude about receiving recycled water at homes. Similarly, significant positive relationship was observed between acknowledgement of the importance of recycled water and willingness to use recycled water for washing machines and acknowledgement of the importance of recycled water and overall support for the use of recycled water in washing machines. Mild positive significant relationship was revealed 
between willingness to use recycled water for washing machines and overall support for the use of recycled water for washing machines $(\mathrm{r}=0.4, \mathrm{p}=0.000)$ among the non-user group and the current user group $(\mathrm{r}=0.4, \mathrm{p}=0.000)$ whereas only weak positive significant relationship was observed $(\mathrm{r}=0.2, \mathrm{p}=0.000)$ among the perspective user group of recycled water (Table 4$)$. In addition to this, among the perspective user group, weak positive relationship was observed between acknowledgement of the importance of recycled water and willingness to use recycled water for washing machines $(\mathrm{r}=0.2, \mathrm{p}=0.006)$ and acknowledgement of the importance of recycled water and overall support for the use of recycled water in washing machines $(\mathrm{r}=0.3, \mathrm{p}=0.000)$. This gives us the general idea that the residents in this area acknowledged the importance of recycled water and they are happy to use the recycled water for less contact uses; however, they are reserved to use the same for high contact uses like washing clothes.

\section{Table 4.}

\subsection{Cost of recycled water and information on recycled water}

Regarding the cost of recycled water, as presented in Figure 5, the respondents who thought the cost of the recycled water to be lower than that of drinking water occupied $45 \%, 55 \%$ and $47 \%$ from non-user, perspective user and current user categories respectively. $19 \%$ of the respondents from the non user group, $15 \%$ from the perspective user group and $31 \%$ from the current user group are of the opinion that the price would remain same as that of drinking water.

\section{Figure 5.}

In a question about the information or updates on recycled water provided to the community, as expected in the non user community, the higher percentage of respondents $(81 \%)$ revealed to have not enough information on recycled water supply to their homes $\left(\chi^{2}=\right.$ $178.24, \mathrm{df}=2, \mathrm{p}=0.000)$. However, remarkable percentage of respondents $(65 \%$ and $45 \%)$ 
from the perspective and current user group also reckoned to have not enough information which was unexpected results. $11 \%$ from non user, $22 \%$ from perspective user and $45 \%$ of current user group expressed to be well informed about this $\left(\chi^{2}=179\right.$, df $\left.=2, p=0.000\right)$ while $8 \%$ from non user, $12 \%$ from perspective user and 15\% from current user are unsure about the information or updates on recycled water provided to the community.

Information always plays an important role and influences the community's acceptance rate of recycled water (Roseth, 2008). Therefore, due consideration should be given to this aspect prior to the implementation of the new end use of recycled water. Most of the respondents $(76 \%)$ had chosen brochures or the educational leaflets as the best method for them to get information on recycled water followed by articles or advertisements in newspapers $(58 \%)$ and website or e-mail (35\%). Personal visit by the concerned authorities were not much favoured by the general public. Hardly $20 \%$ chose this option and generally the people from the age group 50 to $60+$ were supporting this option. This may be attributed to the reason that the preoccupation about health aspects among others increases with increasing age.

\subsection{Feedbacks from the current user of recycled water}

In Newington Sydney, the respondents were asked if they are using recycled water for six end uses listed as flushing toilets, watering gardens, washing cars, washing cloths, filling a swimming pool and showering. Results from Figure 6 clearly shows that the percentage of respondents using recycled water for flushing toilets (94\%), watering gardens $(91 \%)$ and washing cars $(86 \%)$ are very high. This findings is in line to the statements made by many researcher (Hurlimann 2008; Roseth 2008; Pham et al., 2011; Mainali et al., 2011) that the uses of recycled water in the existing dual reticulation system is confined within toilet flushing, garden irrigation and car washing. About 5\% of the respondents are unsure if they are using recycled water for flushing toilets and irrigating gardens though they are aware that they have dual pipe system at home. Almost 3\% revealed that they are not using recycled 
water for garden watering as they are living in an apartment. $86 \%$ of the respondents are using recycled water for washing their cars whereas $9 \%$ of the respondents are not using recycled water for washing their cars. Few of them reckoned to wash their cars at car washing parlours and few of them revealed that they used the recycled water to wash their cars in the beginning but found out the patches/spots on the car body surface. Hence, they stopped washing cars with recycled water.

\section{Figure 6.}

$65 \%$ of the respondents claimed they are not using recycled water for washing machines whereas $24 \%$ of the respondents claimed they are unsure about the connection of recycled water line to their washing machines and are not really sure about it. $16 \%$ of the respondents claimed they are already using recycled water in washing machines without any major problems. Among those who claimed to be using recycled water already when asked if they are concerned on the effects of recycled water on cloth colour, potential damage to cloth, potential odour and effect on washing machine, $100 \%$ answered with no concern to all as their reply. Instead few complain about the consumption of more detergent which they believe is because of the result of strong hardness of the water. Otherwise they all seem to be very happy about using recycled water in washing machine.

In a question about the level of satisfaction, $80 \%$ of the respondents revealed that they are satisfied among which $20 \%$ reckoned to be very satisfied with the recycled water to present $\left(\chi^{2}=69, \mathrm{df}=4, \mathrm{p}=0.000\right)$. The $\%$ of respondents not satisfied with the recycled water is only $4 \%$. When the respondents were asked if they have any specific complains or concerns regarding the quality of recycled water, $70 \%$ of the respondents reckoned to have no specific complain. However, few respondents $(7 \%)$ revealed colour of the recycled water as their specific concern and few (10\%) revealed odour, saltiness, and clearness of recycled water as their major specific concerns. Few of the respondents who are already using recycled water 
for washing machines, claimed that due to the higher salinity problem excess amount of detergent is required to wash clothes in washing machines as mentioned above. Very few are disappointed because of the suspended soil like particles seen in the toilet pan after flushing while few did complain about the spots appeared in the cars after washing with recycled water. Health issues were picked up as their major concern by only $6 \%$ of the respondents and many believe that the recycled water so supplied by the concerned authorities is safe enough without any health effects. Only $1 \%$ revealed cost as the major concern. Almost 75\% of the respondents are quite happy and very happy to receive recycled water in their homes whereas $20 \%$ of the respondents are unsure about it and $4 \%$ and $1 \%$ are not happy and very unhappy respectively.

In an overall analysis, it is observed that the community in Newington in Sydney are very happy to make use of recycled water fit for purpose end uses. They actually feel very proud for being able to conserve huge amount of drinking water replacing with recycled water and contributing on sustainable urban water management. The community believe that the dual reticulation system should be the model for all future developments and should also be retro fitted to the existing developments.

\section{Conclusions}

The results of this study provide crucial information on community's perception to recycled water use for household laundry. Generally, the survey shows a considerable support for the notion of using recycled water for the new end use.

Among the listed end uses of recycled water, as expected, lesser support was observed for the uses with higher physical contacts. 
$>$ In addition to the health issues, community's basic concerns regarding the new end use are the impact of recycled water on the colour of clothes, potential damage to cloth, potential damage to the washing machine and potential odour.

Among the three categories of user groups of recycled water, the perspective user are more concerned and have more reservations for the use of recycled water in washing machines.

$>$ The current users of the recycled water in Newington are very happy with the supply of recycled water and are willing to accept the new end use to the system.

$>$ The non-users group show less concerns and are more willing to use recycled water for laundry.

The information presented in this paper can be beneficial for recycled water retailers and decision makers, who aim to introduce water recycling schemes via dual pipe system in the urban communities to ensure sustainable urban water. The introduction of washing machine as a new end use of recycled water in urban Australian suburbs is acceptable by the communities involved.

\section{Acknowledgement:}

This work was funded by Australian Research Council (ARC) Industry Linkage Grant (LP100100494). The authors also acknowledge the supports from Port Macquarie Hasting Council, Gold Coast Water, City West Water and Sydney Olympic Park Authority.

\section{References-}

ABS (Australian Bureau of Statistic), 2008. Environmental issues: Energy use and conservation. Available from

http://www.abs.gov.au/Ausstats/ABS@.nsf/Latestproducts/0E43C98B32A7FE85CA25750E 00109A1D?opendocument

ABS (Australian Bureau of Statistics), Census quick stats, 2011a. Availble from 
http://www.censusdata.abs.gov.au/census_services/getproduct/census/2011/quickstat/SSC11 898?opendocument\&navpos $=220$

ABS (Australian Bureau of Statistics), Census quick stats, 2011b. Availble from http://www.censusdata.abs.gov.au/census_services/getproduct/census/2011/quickstat/2GMEL

ABS (Australian Bureau of Statistics), 4602.0.55.001 - Environmental Issues: Energy Use and Conservation $2011 \mathrm{c}$. Available from

http://www.abs.gov.au/AUSSTATS/abs@.nsf/Latestproducts/4602.0.55.001Main\%20Feature s6Mar\%202011 ?opendocument\&tabname $=$ Summary\&prodno $=4602.0 .55 .001 \&$ issue $=\mathrm{M}$ $\operatorname{ar} \% 202011 \&$ num $=\&$ view $=$

ABS (Australian Bureau of Statistics), 3235.0 - Population by Age and Sex, Regions of Australia, 2011d. Available from:

http://www.abs.gov.au/ausstats/abs@.nsf/Products/3235.0 2011 Main+Features New+Sout $\mathrm{h}+$ Wales?OpenDocument.

ABS (Australian Bureau of Statistics), 1301.0 - Year Book Australia, 2012. Available from:

http://www.abs.gov.au/ausstats/abs@.nsf/Lookup/by\%20Subject/1301.0 2012 Main\%20Fea tures $\sim$ Water 279 .

Ahmad S. Public attitude towards water and water reuse. Wat. Sci. Techno., 1991; 23(1012):2165-2170.

Albrechtsen HJ. Microbiological investigations of rainwater and graywater collected for toilet flushing. Water Sci. Techno., 2002; 46(6-7):311-316.

Alhumoud JM, Madzikanda D. Public perceptions on water reuse options: The case of Sulaibiya wastewater treatment plant in Kuwait, International Business \& Economics Research Journal, 2010; 1(9):141-158.

Bruvold WH. Public attitudes toward reuse of reclaimed water. 1972. University of California, Water Resources Centre, California.

Bruvold WH . Public opinion on water reuse options. Journal of the Water Pollution Control Federation, 1988; 60(1):45-49.

Bruvold WH, Olson BH, Rigby M. Public Policy for the Use of Reclaimed Water Environmental Management, 1981; 5(2):95-107.

Bruvold WH, Ward PC. Public attitudes toward uses of reclaimed wastewater. Water and Sewage Works, 1970; 117:120-122.

Chen Z, Ngo HH, Guo WS, Listowski A, O'Halloran K, Thompson M, Muthukaruppan M. Multi-criteria analysis towards the new end use of recycled water for household laundry: A case study in Sydney. Sci. Total Environ 2012; 438:59-65.

Dolnicar S, Scha” fer AI. Desalinated versus recycled water: public perceptions and profiles of the accepters. Journal of Environmental Management 2009; 90 (2):888-900.

Friendler E, Lahav O, Jizhaki H, Lahav T. Study of urban population attitudes towards various wastewater reuse options: Israel as a case study. Journal of Environmental Management 2006; 81:360-370.

Hartley TW. Water Reuse: Understanding public perception and participation. Virginia, Water Environment Research Foundation; 2003. 
Higgins J, Warnken J, Sherman PP, Teasdale PR. Survey of users and providers of recycled water: quality concerns and directions for applied research Water Research 2002; 36(2002):5045-5056.

Hills S, Birks R, McKenzie B. The Millennium Dome "Watercycle" experiment to evaluate water efficiency and customer perception at a recycling scheme for 6 million visitors. Water Sci Techno, 2002; 46(6-7):233-240.

Hurlimann A. An Exploration of Community Attitudes to Recycled Water Use - An Urban Australian Case Study, PhD, The University of South Australia, Adelaide, 2006a.

Hurlimann A. Melbourne Office Worker Attitudes to Recycled Water Use. Water Journal of the Australian Water Association, 2006b; 33(7):58-65.

Hurlimann A. Community attitudes to recycled water use - An urban Australian case study, part 2. Research Rep. No. 56, Cooperative Research Centre for Water Quality and Treatment. Salisbury, South Australia, 2008.

Hurlimann A, Mackay JM. What attributes of recycled water make it fit for residential purposes? The Mawson Lakes experience. Desalination 2006; 187:167-77.

Hurlimann A, McKay J. Urban Australians using recycled water for domestic non-potable use - An evaluation of the attributes price, saltiness, colour and odour using conjoint analysis " Journal of Environmental Management, 2007; 83(1):93-104.

Iarossi G. The power of survey design: a user's guide for managing surveys, interpreting results and influencing respondents. Washington, DC: World Bank; 2005.

Jeffrey P. Public Attitudes to In-House Water Recycling in England and Wales. Water and Environmental Management: Journal of the Chartered Institution of Water and Environmental Management 2002; 16(3):214-217.

Jeffrey P, Jefferson B. Public receptivity regarding in-house water recycling: results from a UK survey. Water Science and Technology: Water Supply 2003; 3:109-116.

Lohman LC, Milliken JG. Informational/Educational Approaches to Public Attitudes on Potable Reuse of Wastewater. U.S. Department of the Interior, Denver, 1985.

Marks J. Advancing community acceptance of reclaimed water. Water Journal of the Australian Water Association, 2004; 31(5):46-51.

Marks JS, Martin B, Zadoroznyj M. Acceptance of Water Recycling In Australia: National Baseline Data." Water Journal of the Australian Water Association, 2006; 33(2):151-157.

Madany I M, Al-Shiryan A, Lori I and Al-Khalifa H (1992) Public awareness and attitudes toward various uses of renovated water. Environment International 1992;18: 489-95.

Mainali B, Ngo HH, Guo W, Pham TTN, Johnston A (2011 a). Feasibility assessment of recycled water use for washing machines in Australia through SWOT analysis. Resour Conser Recyc 2011; 56 (2011): 87-91.

Mainali B, Ngo HH, Guo W, Pham TTN, Johnston A (2011b) SWOT analysis to assist identification of the critical factors for the successful implementation of water reuse schemes Desalination and water treatment.

Mainali B, Pham TTN, Ngo HH, Guo WS. Maximum allowable values of the heavy metals in recycled water for household laundry, Science of the total environment 2012; 452453:427-432. 
Nancarrow B, Leviston Z, Po M, Porter N, Tucker D. What drives communities' decisions and behaviours in the reuse of wastewater. Water Sci and Techno 2008; 57(4):485-491.

Ngo HH, Chuang H, Guo WS, Ho DP, Pham TTN, Johnston A, Lim R, Listowski A. Resident's strategy survey on a new end use of recycled water in Australia. Desal and Water Treatm 2009; 11:93-97.

O'Toole J, Leder K, Sinclair MA. Series of exposure experiments -recycled water and alternative water sources: Part B - Microbial transfer efficiency during machine clothes washing and microbial survival turf grass experiments. Rep. No. 46, Cooperative Research Centre for water quality and treatment. Salisbury, South Australia, 2008.

Pakula C, Stamminger R. Electricity and water consumption for laundry washing by washing machine worldwide. Energy efficiency. Springer Netherlands. ISSN 1570-646X (Print) 1570-6478 Online First TM, 7 Jan, 2010.

Pham TTN, Ngo HH, Guo WS, Dang HPD, Mainali B, Johnston A, Listowski A. Responses from general community to the possible use of recycled water from washing machines: A case study in Sydney, Australia , Resour Conserv Recy. 2011; 55:535-540.

Po M, Kaercher JD, Nancarrow BE. Literature review of factors influencing public perceptions of water reuse, CSIRO Land and Water, Perth, 2003, p.1-39.

Radcliffe J. Water recycling in Australia. A review undertaken by the Australian academy of technological sciences and engineering. Victoria, Australia, 2004.

Roseth N. Community views on recycled water - the impact of information. Research report no. 48, Cooperative Research Centre for water quality and treatment. Salisbury, South Australia, 2008.

Sims JH, Baumann DD. Renovated waste water: The question of public acceptance, Water resources research, 1974; 10(4).

SPSS Inc. (2007). Statistical Package for the Social Sciences, Chicago, IL: SPSS.

Stone R, Company Incorporated. Wastewater Reclamation: Socio-Economics, Technology, and Public Acceptance. U.S Department of the Interior, Los Angeles, 1974.

Storey MV. Addressing aesthetic and technical issues associated with the use of recycled water in washing machine. Sydney Water Corporation, 2009.

Sydney Water. Community views on re-cycled water. Research Report, Sydney Water, Sydney, 1999.

Tsagarakis KP, Mellon R, Stamataki E, Kounalaki E. Identification of recycled water with an empirically derived symbol increases its probability of use. Enviro Sci and Techno, 2007; 41 (20):6901-6908.

Van der Hoek JP, Dijkman BJ, Terpstra GJ, Uitzinger MJ, Van Dillen MRB. Selection and evaluation of a new concept of water supply for "Ijburg" Amsterdam. Water Sci and Techno, 1999; 39:33-40.

Whiteoak K, Jones P, Pickering P. Progress against the national target of 30\% of Australia's wastewater being recycled by 2015, Marsden Jacob Associates, 2012. Available from:

(http:/www.google.com.au/url?sa=t\&rct=j\&q=\&esrc=s\&source=web\&cd=2\&cad=rja\&ved= 0CDoQFjAB\&url=http\%3A\%2F\%2Fwww.environment.gov.au\%2Fwater\%2Fpublicatio ns $\% 2$ Furban $\% 2$ Fpubs $\% 2$ Frecycled-water-target-final- 
report.docx\&ei=rjrrUOT1A4uikgXO34CQBQ\&usg=AFQjCNF1iybiXyRTo9Fmy6IrmY dAmQH7Cw\&bvm=bv.1355534169,d.dGI)

Zar JH, Biostatistical Analysis. Fifth edition, Prentice Hall, Upper Saddle River, NJ, 2010. 
Table 1: Percentage of respondents opposing the specific uses of recycled water- Various international studies.

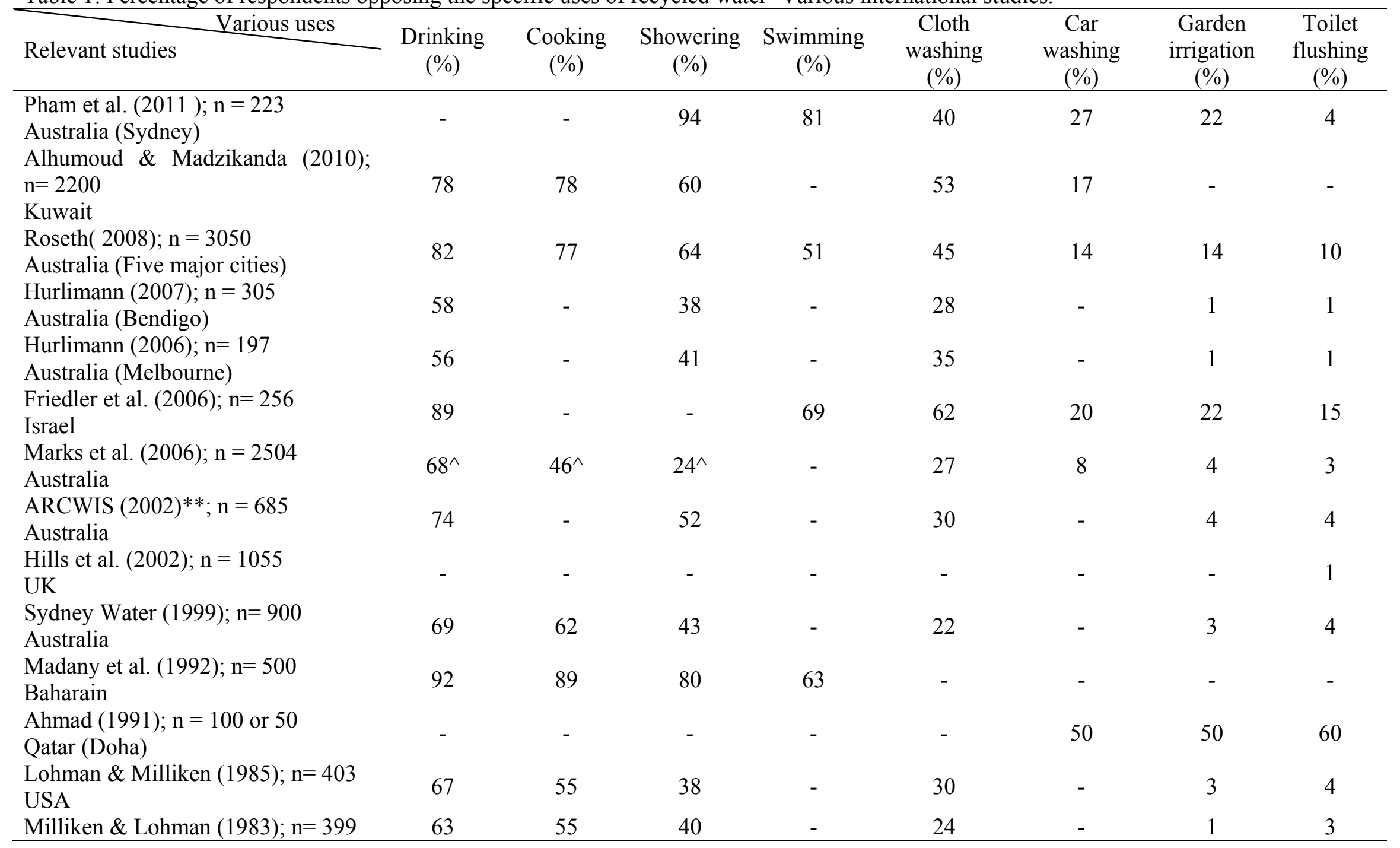




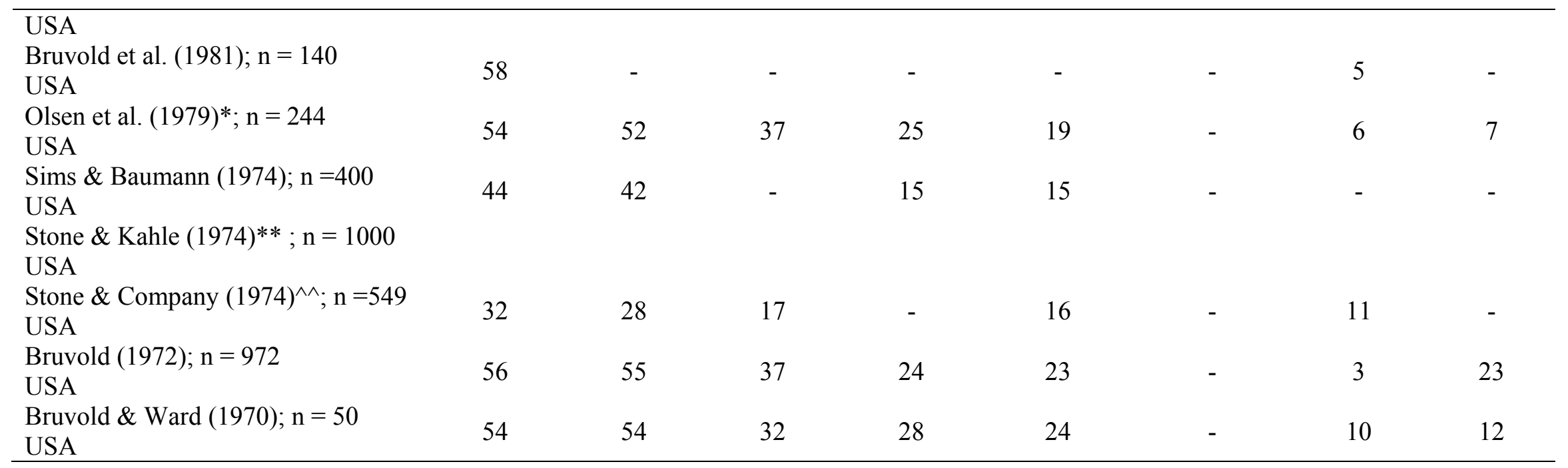

*Cited in Bruvold (1988) **Cited in Po et al. (2003) ^^Cited in Hurlimann (2008)

${ }^{\wedge}$ Question phrased 'water mixed with recycled water and treated to drinking water quality 
Table 2: General details of all three study areas.

\begin{tabular}{|c|c|c|c|c|c|}
\hline & & Total & $\begin{array}{l}\text { Port } \\
\text { Macquarie }\end{array}$ & Melbourne & Sydney \\
\hline Sample Size & $\mathrm{N}$ & 478 & 175 & 152 & 151 \\
\hline \multirow{2}{*}{ Gender (\%) } & Males & 45 & 47 & 37 & 52 \\
\hline & Females & 55 & 53 & 63 & 48 \\
\hline \multirow{6}{*}{ Age $(\%)$} & $18-29$ & 4 & 3 & 5 & 5 \\
\hline & $30-39$ & 32 & 32 & 36 & 29 \\
\hline & $40-49$ & 32 & 24 & 33 & 39 \\
\hline & $50-59$ & 15 & 21 & 13 & 11 \\
\hline & $60+$ & 13 & 20 & 11 & 9 \\
\hline & $1-3$ & 53 & 70 & 41 & 47 \\
\hline \multirow{3}{*}{ Household size (\%) } & $4-6$ & 44 & 29 & 55 & 52 \\
\hline & $7-9$ & 3 & 1 & 4 & 1 \\
\hline & $>10$ & 0 & 0 & 0 & 0 \\
\hline \multirow{3}{*}{$\begin{array}{c}\text { Washing Machine } \\
\text { type }(\%)\end{array}$} & Top loading & 65 & 72 & 65 & 58 \\
\hline & Front loading & 30 & 28 & 35 & 42 \\
\hline & $1-2$ times & 35 & 36 & 37 & 31 \\
\hline Wash & 3-4 times & 38 & 41 & 29 & 45 \\
\hline \multirow[t]{3}{*}{ Frequency/week (\%) } & 5-6 times & 12 & 10 & 14 & 11 \\
\hline & $>7$ times & 15 & 13 & 19 & 14 \\
\hline & Powder & 55 & 54 & 60 & 51 \\
\hline \multirow{5}{*}{$\begin{array}{c}\text { Wash detergents } \\
\text { type }(\%)\end{array}$} & Liquid & 25 & 34 & 18 & 21 \\
\hline & Mixture & 20 & 12 & 22 & 27 \\
\hline & Powder and & & & & \\
\hline & Liquid & & & & \\
\hline & Strongly & 30 & 29 & 32 & 30 \\
\hline \multirow{4}{*}{$\begin{array}{l}\text { Acknowledgement } \\
\text { of importance of } \\
\text { recycled water }(\%)\end{array}$} & Agree & & & & \\
\hline & Agree & 61 & 57 & 62 & 64 \\
\hline & Disagree & 7 & 10 & 4 & 5 \\
\hline & $\begin{array}{l}\text { Strongly } \\
\text { disagree }\end{array}$ & 2 & 4 & 2 & 1 \\
\hline \multirow{6}{*}{$\begin{array}{c}\text { Attitude about } \\
\text { receiving recycled } \\
\text { water }(\%)\end{array}$} & Very happy & 35 & 23 & 32 & 31 \\
\hline & Quite happy & 40 & 47 & 47 & 51 \\
\hline & Unsure/don't & 12 & 23 & 16 & 16 \\
\hline & know & & & & \\
\hline & Not happy & 12 & 5 & 3 & 3 \\
\hline & Very unhappy & 1 & 2 & 1 & 1 \\
\hline
\end{tabular}


Table 3: Wilcoxon Signed Ranks Test for ranking the most preferred condition by the community which would make them more confident to use recycled water in washing machine

\begin{tabular}{|c|c|c|c|c|c|c|}
\hline & KNW & REA & HAV & WAT & DUAL & NOT \\
\hline KNW & & $Z=-5.108$ & $\mathrm{Z}=-4.306$ & $Z=-4.180$ & $Z=-4.412$ & $Z=-5.126$ \\
\hline REA & & & & & & $\mathrm{Z}=-7.729$ \\
\hline HAV & & & & & $Z=-1.97$ & $\mathrm{Z}=\mathbf{- 8 . 2 1 4}$ \\
\hline WAT & & & & & & $\mathrm{Z}=-7.509$ \\
\hline DUAL & & & & & & $Z=-8.062$ \\
\hline
\end{tabular}

Bold number:Level of significance $\mathrm{P}=0.000$

Italic number: Level of significance at $\mathrm{p}<0.05$

KNW- Knowing that recycled water saves valuable drinking water

REA- Reading about recycled water being used in washing machines by other customers

HAV- Having a small unit of pre-treatment of water to assure the quality and safety of water

WAT- Watching a scientist or expert recommends the use of recycled water in washing machines

DUAL- Knowing that recycled water will be supplied to your home together with drinking water using separate pipe lines

NOT- I could not be assured 
Table 4: Correlation between variables

\begin{tabular}{|c|c|c|c|c|c|c|}
\hline & & $\begin{array}{l}\text { Washing } \\
\text { frequency }\end{array}$ & $\begin{array}{l}\text { Acknowledge the } \\
\text { importance of } \\
\text { recycled water }\end{array}$ & $\begin{array}{l}\text { Attitude about } \\
\text { receiving } \\
\text { recycled water }\end{array}$ & $\begin{array}{l}\text { Willingness to } \\
\text { use recycled } \\
\text { water }\end{array}$ & $\begin{array}{l}\text { Overall } \\
\text { Support }\end{array}$ \\
\hline $\mathrm{P}$ & & --- & $\begin{array}{c}r=-0.2 \\
p=0.009\end{array}$ & $\begin{array}{c}\mathrm{r}=-0.2 \\
\mathrm{p}=0.02\end{array}$ & --- & --- \\
\hline M & Gender & --- & --- & --- & --- & --- \\
\hline $\mathrm{S}$ & & $\begin{array}{c}r=0.25 \\
p=0.002\end{array}$ & --- & --- & $\begin{array}{c}\mathrm{r}=0.2 \\
\mathrm{p}=0.05\end{array}$ & --- \\
\hline $\mathrm{P}$ & & & $\begin{array}{l}r=-0.2 \\
p=0.02\end{array}$ & $\begin{array}{c}r=-0.18 \\
p=0.02\end{array}$ & --- & --- \\
\hline M & Age & $\begin{array}{l}r=-0.19 \\
p=0.02\end{array}$ & & $\begin{array}{c}\mathrm{r}=-0.16 \\
\mathrm{p}=0.05\end{array}$ & --- & --- \\
\hline $\mathrm{S}$ & & & $\begin{array}{c}r=0.2 \\
p=0.03\end{array}$ & & --- & --- \\
\hline $\mathrm{P}$ & & --- & -- & $\begin{array}{c}\mathrm{r}=0.65 \\
\mathrm{p}=0.000\end{array}$ & $\begin{array}{c}r=0.2 \\
p=0.006\end{array}$ & $\begin{array}{c}r=0.43 \\
p=0.00\end{array}$ \\
\hline $\mathrm{M}$ & $\begin{array}{l}\text { Acknowledge the } \\
\text { importance of } \\
\text { recycled water }\end{array}$ & --- & -- & $\begin{array}{c}r=0.52 \\
p=0.000\end{array}$ & --- & --- \\
\hline $\mathrm{S}$ & & --- & -- & $\begin{array}{c}\mathrm{r}=0.33 \\
\mathrm{p}=0.000\end{array}$ & --- & $\begin{array}{c}r=0.3 \\
p=0.000\end{array}$ \\
\hline
\end{tabular}


P

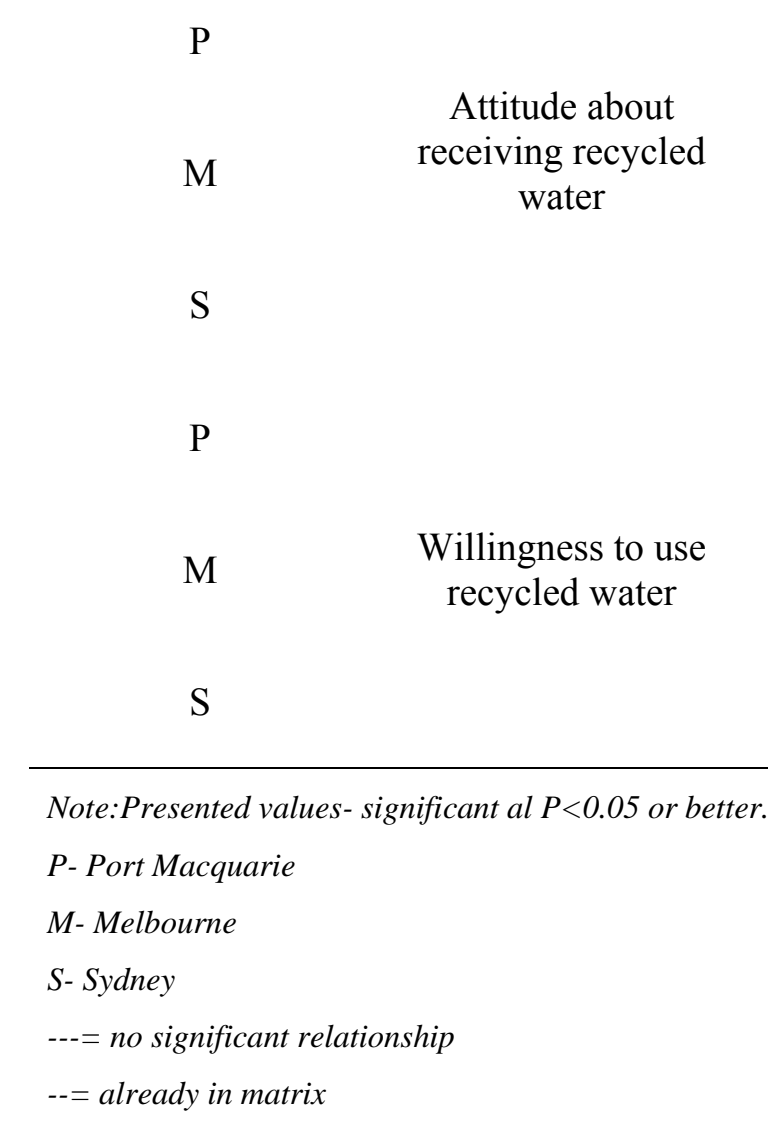




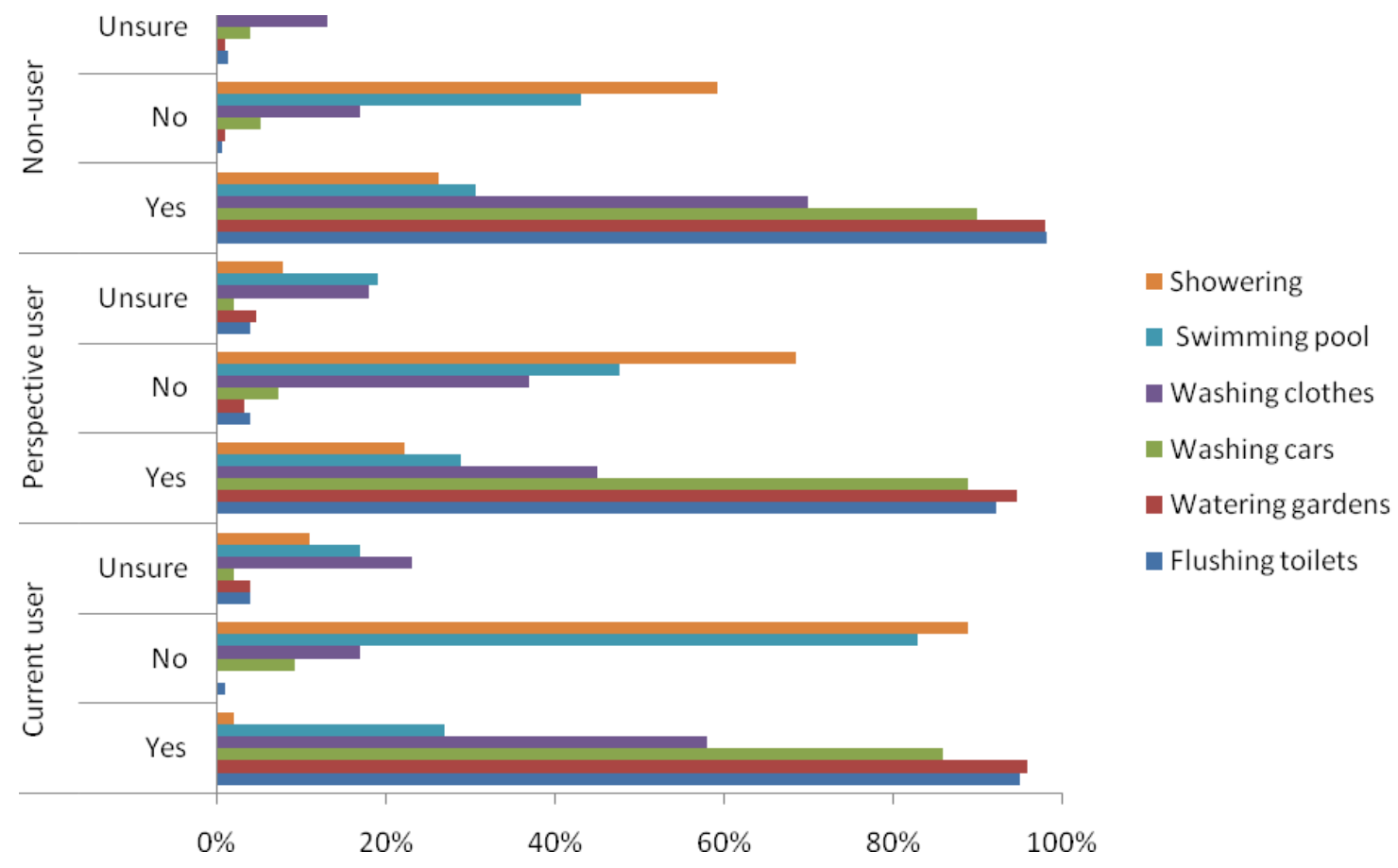

Figure 1. Willingness to use recycled water for various enduses for three categories of users of recycled water 


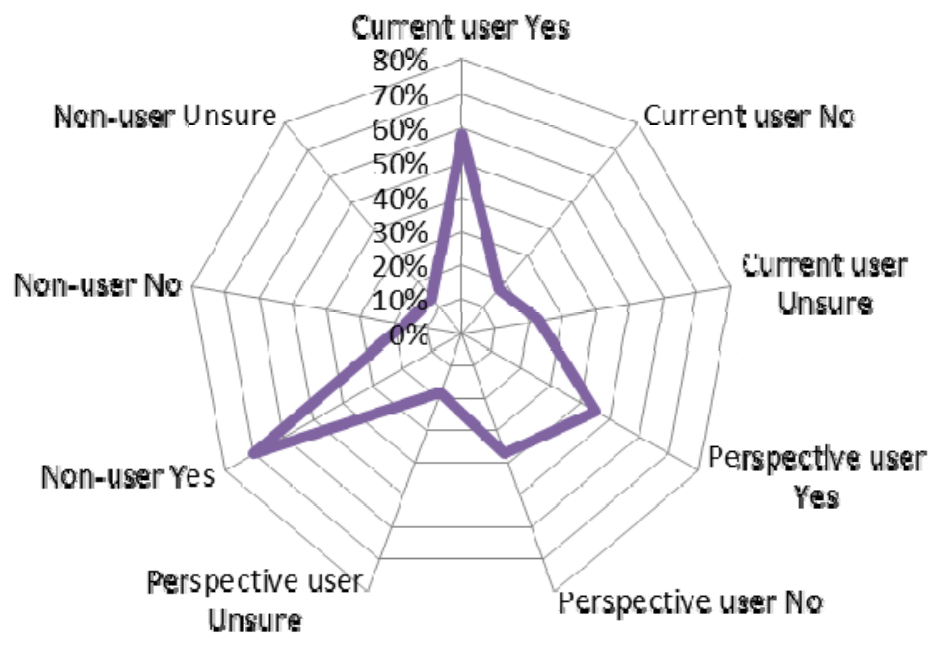

Washlng clothes

Figure 2. Comparitive analysis of willingness to use recycled water for washing machine among three user categories of recycled water. 


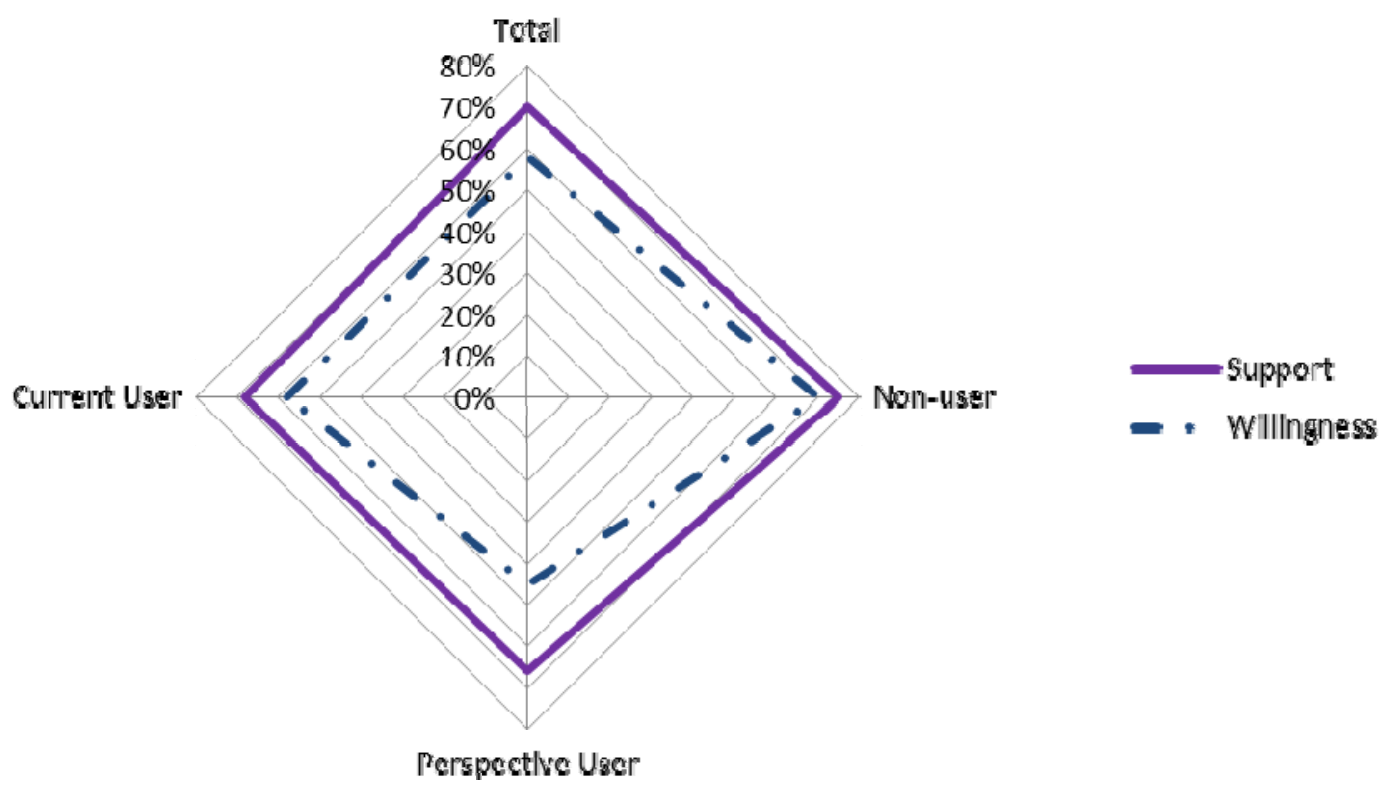

Figure 3. Percentage difference among the three user groups in terms of their willingness to use recycled water for washing machine and to support the new end use. 


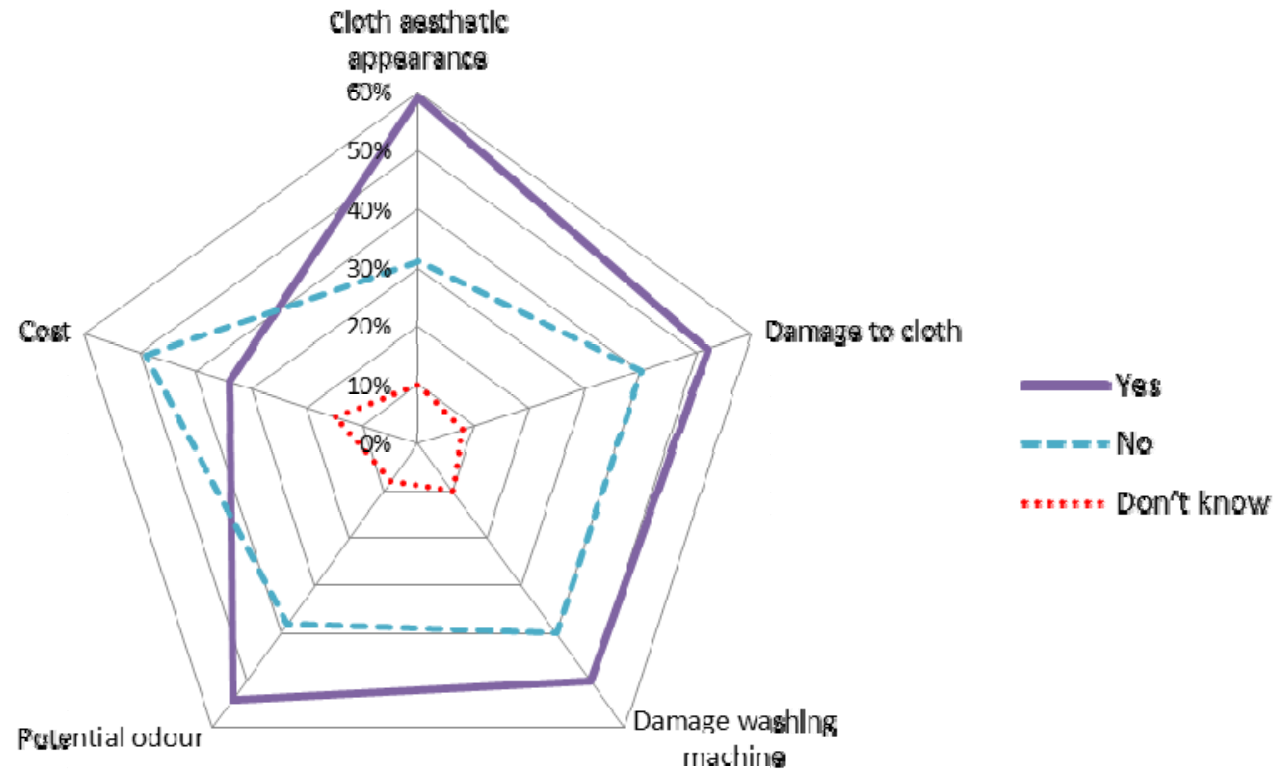

Figure 4. Concerns of the community regarding the use of recycled water for washing machine. 


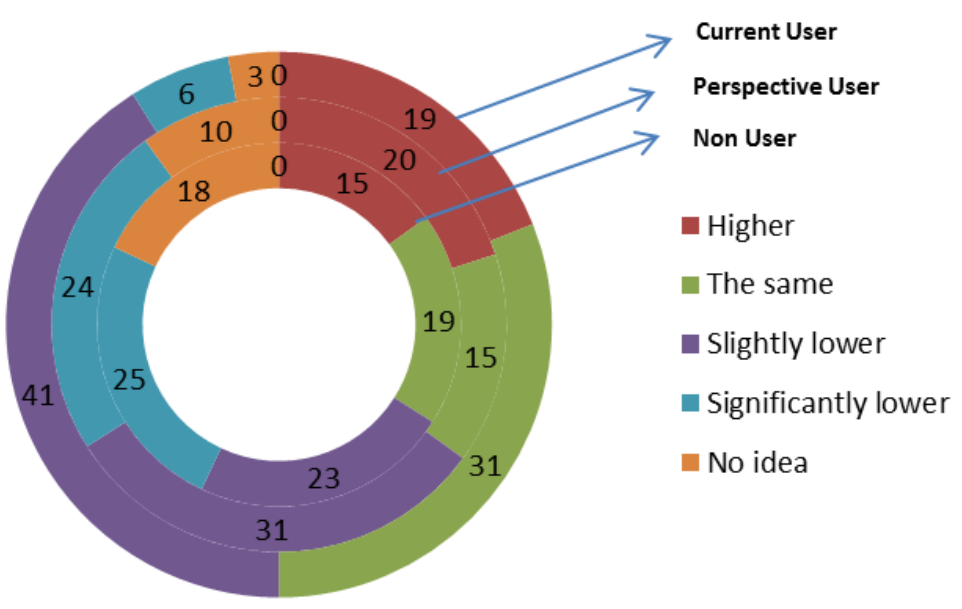

Figure 5. Percentage of respondents in regards to their opinion about the cost of recycled compared to that of drinking water among the three user groups. 


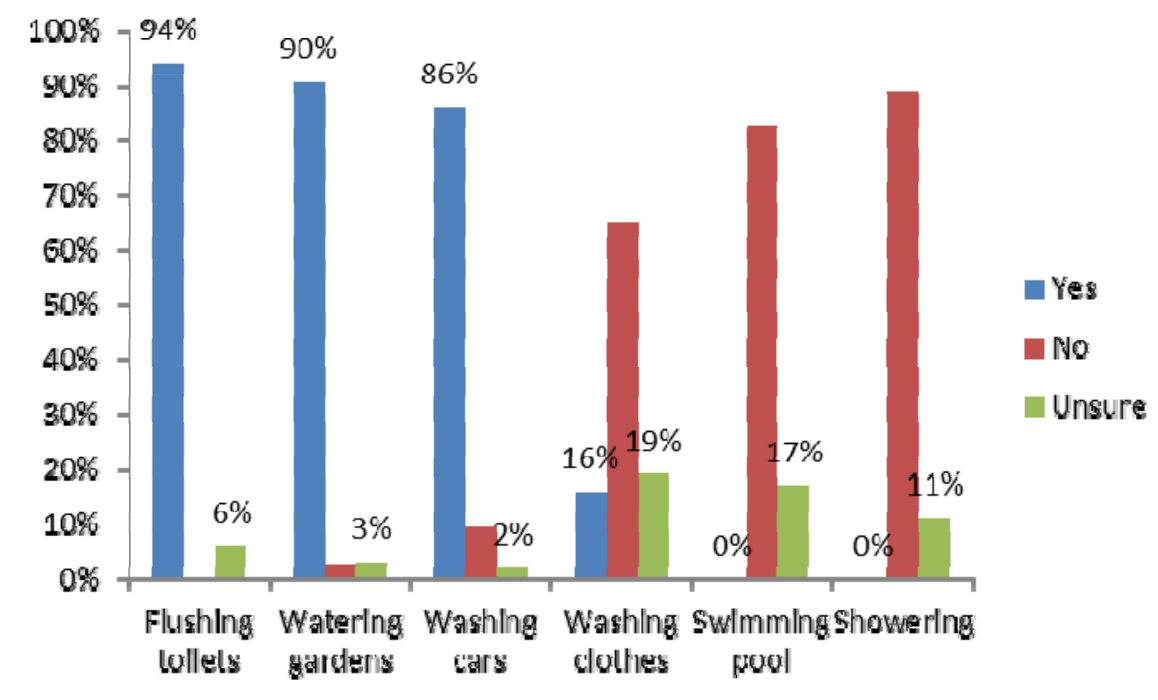

Figure 6. Current use of recycled water for various enduses in Newington 